\title{
"We didn't expect dementia and diapers": Reflections on the Nihon experience with type $A$ aortic dissection in octogenarians
}

Martin F. McKneally, MD, PhD

See related article on page 1042.
From the Department of Surgery and Joint Centre for Bioethics, University of Toronto, Toronto, Ontario, Canada.

Received for publication Oct 17, 2007; accepted for publication Oct 25, 2007.

Address for reprints: Martin F. McKneally, $\mathrm{MD}, \mathrm{PhD}$, Department of Surgery and Joint Centre for Bioethics, University of Toronto, 77 Forest Grove Dr, Toronto, ON M2K 1Z4, Canada (E-mail: martin.mckneally@ utoronto.ca).

J Thorac Cardiovasc Surg 2008;135:984-5 $0022-5223 / \$ 34.00$

Copyright $(\underset{2008}{ } 20 y$ The American Association for Thoracic Surgery

doi:10.1016/j.jtcvs.2007.10.068

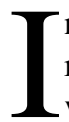
$\mathrm{n}$ this issue, Mitsumasa Hata and his colleagues ${ }^{1}$ at the Nihon University in Tokyo report their experience with emergency surgical intervention in octogenarians with acute type A aortic dissection. They move us from a lively earlier discussion in the Journal, based on the Siena experience, of the medical factors salient to answering the question of whether we "should" be doing this ${ }^{2-6}$ to a deeper level of discourse about the quality of life of patients and their families after surgical treatment. "Because we surgeons looked after the patients in our outpatient clinic," Hata's group realized and reflected thoughtfully on some of the troubling unfavorable intermediate and long-term outcomes. Of 30 patients treated surgically, 4 died, 5 became bedridden because of cerebral damage or severe depression after surgical intervention and subsequently died during institutional care, and 13 died of various unrelated illnesses or injuries in late follow-up.

The 50 octogenarian patients "were divided into 2 groups, 31 underwent emergency surgery, 28 were treated conservatively because the patient or family refused surgery." Every surgeon will recognize the undescribed nuances of this sorting process, the shades of meaning presented to families that inclines them toward or away from consenting to surgical treatment. This is part of the burden of surgeons, who give their own informed consent to accept and endure the responsibility and consequences of these decisions.

Questions that begin with "should" signal the need for explicit discussion of ethics: the values and principles that guide our decisions and actions. Mark Siegler and Peter Angelos, in the Surgical Ethics Program at the University of Chicago's MacLean Center for Clinical Medical Ethics (http://medicine.uchicago.edu/centers/ ccme/events.htm) use a 4-component approach to ethical decision making that we can apply here. ${ }^{7}$

1. Medical factors: What critical determinants of mortality and postoperative morbidity are present, such as preoperative stroke, renal and respiratory insufficiency, myocardial ischemia, congestive failure, and hemodynamic instability? ${ }^{5}$

2. Preferences: Would the patient and the family prefer to be spared the potentially degrading or disabling effects and side effects of surgical treatment? Would the surgical team and the family prefer to minimize regret by "doing everything that can be done" regardless of consequences? The authors' description of refusal to pay and bitter resentment expressed by families of patients who were demented and bedridden after surgical intervention and the gratitude of families of patients who died during surgical intervention illustrate two outcomes of heroic treatment. Unfortunately, these are knowable only after the decision to operate has been made. Among families of patients who did not undergo operations none complained or refused to pay. Presumably they assigned responsibility for tragic outcomes to disease and age, rather than the surgical team.

3. Quality of life: What was the quality of the patient's life before dissection, and what will it be during and after treatment? Many patients in their ninth decade, including some of those who refused treatment by Hata and colleagues, prefer an abrupt and definitive end to their lives rather than slow or disabled deterioration. This abrupt rectangulation of the life curve is difficult for family members to accept when they 
confuse versions of the patient's life role, remembered from an earlier era, with the present octogenarian version.

4. Contextual features: What are the social, economic, or institutional factors that might have important effects on this fateful decision? The patient's role as the caregiver of others or the ability of the family to provide care should disabling complications arise are important factors in the decision process.

The 4-part analysis helps identify and sort octogenarians into manageable groups, such as the risk averse, who are resigned to their mortality, prefer nonsurgical treatment, and have adequate home care, or lower-risk patients determined to take on the challenge and able to accept and afford longterm care should tragic complications develop. The undescribed groups between these extremes require discerning surgical judgment. Integrating the attributes, goals, and circumstances into this analytic framework helps decision makers evaluate each patient holistically. The ethical values and principles that are applied to the framework are respect, beneficence, discernment, and justice.

Respect for the wishes of patients regarding heroic intervention, as expressed in written advance directives, spoken words, or actions reflecting their values and beliefs, shifts decisional responsibility from the family to the individual patient, where it should reside, even when the patient is incapacitated. This value is sometimes undermined through an intellectual slippage toward acting on what the family feels or prefers, such as when organ donors' wishes are overruled by grieving survivors. Written directives have their problems, and designated decision makers who know the patients' preferences, values, and beliefs can more effectively respond to unexpected circumstances. Although my wife is my designated attorney, I talk about my preferences to my children at family gatherings to be sure they will follow my wish not to prolong irremediable illness, tortured to life in an intensive care unit, and to donate whatever I can that might be useful to others. (I am reassured that they understand when they say "Dad, we've got it, it's Christmas, you don't have to remind us....")

Beneficence is the value that inspires us to try to heal, relieve, or rescue when illness or injury strikes, no matter how grave the prognosis. Discernment is the value that helps define the limits of beneficence: the ability to know when inappropriate heroic interventions should be replaced by concentrating on comfort, dignity, and minimizing harm to the patient and family. It is exemplified in sound surgical judgment.

Justice is the value that respects the rights of others to health care resources and fair access to all who need them. Age should not be a disqualifying attribute, although it is intuitively influential when rescue is possible for only one of several in need. Although age is not a morally relevant attribute when considered in itself, it is often a valid surrogate for disqualifying risk factors. ${ }^{5,8}$ Justice requires fair procedures for deciding about allocation of health care resources, not unbending universal rules but particular judgments that admit valid exceptions.

In an earlier discussion of this question, we concluded that individual institutional policies might be set to limit the application of life-saving emergency interventions in most octogenarians with acute aortic dissections, with reasonable exceptions when appropriate. ${ }^{2}$ I recently asked Dr Neri from Siena about the policy he and his colleagues follow now. He replied that little has changed 6 years after our discussion of this question in the Journal. "This is Italy. Politically popular helicopter evacuations from surrounding towns to the central hospital continue to raise expectations of heroic rescue operations to save a 'nonno.' If patients choose surgical treatment, they are not refused." In my own institution, a selective approach is taken; a very small number of octogenarians are offered surgical treatment based on favorable preoperative determinants of outcome, a clear understanding and acceptance of potential disability, and an insurance system that shares the cost of acute and longterm care. ${ }^{9}$

The thoughtful lessons from the experience of the Nihon cardiovascular surgeons emphasize the importance of setting realistic expectations, understanding the longer-term effect of our interventions on families, and understanding the value of discernment. The question they raise remains open, as it should. We are still learning how and when to place reasonable limits on our impulse to rescue all who might benefit from the dramatic technologies of contemporary surgery.

\section{References}

1. Hata M, Sezai A, Niino T, Yoda M, Unosawa S, Furukawa N, et al. Should emergency surgical intervention be performed for an octogenarians with type A aortic dissection? J Thorac Cardiovasc Surg. 2008; 135:1042-6.

2. Neri E, Toscano T, Massetti M, Capannini G, Carone E, Tucci E, et al. Operation for acute type A aortic dissection in octogenarians: is it justified? J Thorac Cardiovasc Surg. 2001;121:259-67.

3. McKneally MF. "We don't do that here": reflections on the Siena experience with dissecting aneurysms of the thoracic aorta in octogenarians. J Thorac Cardiovasc Surg. 2001;121:2002-3.

4. Walker WE. Surgery for acute aortic dissection in octogenarians [letter]. J Thorac Cardiovasc Surg. 2001;122:1049.

5. Ikonomidis JS. Operation for acute type A aortic dissection in octogenarians [letter]. J Thorac Cardiovasc Surg. 2001;122:1050.

6. Hagl C, Griepp RB. Acute type A dissection in octogenarians [letter]. J Thorac Cardiovasc Surg. 2001;122:1050-1.

7. Jonson AR, Siegler M, Winslade WJ. Introduction. In: Jonsen AR, Siegler M, Winslade WJ, editors. Clinical ethics. 4th ed. New York: McGraw-Hill; 1998. p. 1-12.

8. Beauchamp TL, Childress JF. Principles of biomedical ethics. 4th ed. New York: Oxford University Press; 1994. p. 369-72.

9. David TE, Armstrong S, Ivanov J, Barnard S. Surgery for acute type A aortic dissection. Ann Thorac Surg. 1999;67:1999-2001. 